\title{
Match efficiency and firms' hiring standards ${ }^{\sqrt{2}}$
}

\author{
Petr Sedláček ${ }^{\mathrm{a}, *}$ \\ ${ }^{a}$ University of Bonn
}

\begin{abstract}
During the last recession, new hires were lower than would be predicted by a standard matching function and the observed ratio of searching workers and firms. This paper first estimates U.S. match efficiency as an exogenous residual in the matching function using a simple search and matching model. It finds match efficiency to be procyclical and to account for about $1 / 4$ of unemployment increases during the most severe recessions. Second, this paper proposes a model with endogenous separations and firing costs that endogenizes match efficiency, which is driven by firms' hiring standards. The model can explain almost $1 / 2$ of the variation in the initial estimate of match efficiency.
\end{abstract}

Keywords: Match efficiency, estimation, endogenous separations, firms' hiring standards JEL Classification: C32, J63

\section{Introduction}

A popular way to model flows from unemployment to employment is by using a simple (matching) function, typically with aggregate unemployment and vacancies as the only inputs. Such a specification implies that a given number of searching workers and employers always leads to the same number of new hires. In reality this does not always hold, as was evident for instance during the Great Recession, pointing to other sources of variation. In this paper the residual variation in hires, i.e. that not accounted for by unemployment and vacancies, is called "match efficiency". The aim of this paper is to quantify fluctuations in match efficiency, their importance for unemployment and to propose a structural model explaining their underlying driving forces.

To this end, the paper first estimates match efficiency as an unobserved component of the matching function in a simple search and matching model calibrated in a standard fashion. Estimated match efficiency is pro-cyclical with its declines being responsible for $23 \%$ of the unemployment increases during the most severe downturns. Given that match efficiency is an important driver of unemployment fluctuations it is crucial to understand the sources of its variation. As a second step, this paper proposes a model with firing costs and endogenous separations in which movements in match efficiency are not exogenous, but rather an outcome of agents' behavior. Specifically, match efficiency is driven by firms' hiring standards which are endogenously counter-cyclical, as in the data. ${ }^{1}$ The model is able to explain $46 \%$ of the variation in estimated match efficiency.

In the model, workers differ in their productivity levels. There exists a worker productivity threshold below which it is no longer optimal to continue with the employment relationship giving rise to endogenous separations. This threshold rises in recessions as the decline in aggregate productivity renders some previously viable employment relationships suboptimal. For unemployed workers, this represents an increase in firms' hiring standards as firms are willing to hire only the relatively more productive workers. For a given number of unemployed and vacancies this leads to a fall in the number of hires because the fraction of acceptable employment relationships shrinks. In other words, counter-cyclical hiring standards are reflected in pro-cyclical match efficiency movements when one considers a matching function with only aggregate unemployment and vacancies as inputs.

The presence of firing costs drives a wedge between the value of new and existing employment relationships. Because firms require compensation for expected future firing costs, the productivity threshold for newly hired workers is higher than for those in existing relationships. This, together with an upward-sloping density of worker productivity in the lower tail of the distribution, makes firms' hiring standards more sensitive to aggregate fluctuations.

\footnotetext{
This paper is a substantially revised part of my Ph.D. dissertation written at the University of Amsterdam. I thank my advisor Wouter den Haan for his support. I am grateful to Robert King, Ricardo Reis, Antonella Trigari and an anonymous referee for comments that greatly improved this paper. I also thank Charles Bos, Martin Eichenbaum, Bart Hobijn, Pawel Janus, Philip Jung, Keith Kuester, Stephan Fahr, Matija Lozej, Fabien Postel-Vinay, Vincent Sterk, Christian Stoltenberg, Emily Swift, Robert Swift and seminar participants at the ECB, the DNB, Mainz and Amsterdam for comments and inspiring discussions.

*Address: University of Bonn, Adenauerallee 24-42, 53113 Bonn, Germany. Tel.: +49 228739 236. Email: sedlacek@uni-bonn.de

${ }^{1}$ See e.g. Bewley (1999), Devereux (2002), and Quintini (2011).
} 
The empirical part builds on a large body of literature studying and estimating the matching function; see Petrongolo and Pissarides (2001) for an excellent survey. The paper contributes to recent findings that match efficiency declines exacerbated the rise in unemployment during the Great Recession. ${ }^{2}$ Barlevy (2011), Dickens (2011), Lubik (2011) and Veracierto (2011) infer match efficiency from estimates of the matching function within a structural model, Sahin et al. (2011) measure mismatch using the social planner's solution in a theoretical model and Barnichon and Figura (2013) estimate match efficiency as the residual from a matching function regression. Unlike the above-mentioned studies, however, this paper utilizes information from several measures of job filling and finding rates to estimate match efficiency movements and does so on a sample starting already in 1948.

Several recent studies also analyze different channels that can explain changes in match efficiency. Using microdata, Barnichon and Figura (2013) show that fluctuations in match efficiency can be related to the composition of the unemployment pool and dispersion in labor market conditions, Herz and van Rens (2011) highlight the role of mobility decisions across segmented labor markets, Sterk (2010) focuses on geographical mismatch exacerbated by house price movements, Kuang and Valletta (2010) analyze the role of reduced worker search intensity due to extended unemployment benefits, while Davis et al. (2010) stress the role of firms' recruiting intensity. ${ }^{3}$ This paper emphasizes a different channel generating fluctuations in match efficiency that has received little attention so far, namely cyclical changes in firms' hiring standards.

The rest of the paper proceeds as follows: Section 2 introduces a simple search and matching model with exogenous shocks to match efficiency and the estimation procedure. Section 3 presents the estimation results. Section 4 lays out a model with endogenous separations and firing costs and briefly summarizes empirical evidence on counter-cyclical firm hiring standards. Section 5 discusses the calibration and analyzes how well this model explains movements in estimated match efficiency. Finally, Section 6 provides some concluding remarks.

\section{Estimating match efficiency as a structural shock}

The number of new hires, $M_{t}$, is typically modeled using a Cobb-Douglas matching function with constant returns to scale and with unemployment, $u_{t}$, and vacancies, $v_{t}$, as its only inputs. This paper defines match efficiency, $m_{t}$, as the residual of the matching function capturing variation in hires not accounted for by unemployment and vacancies. Under these assumptions the job finding rate, i.e. the rate at which unemployed workers transit into employment, can be written as

$$
f_{t}=M_{t} / u_{t}=m_{t}\left(v_{t} / u_{t}\right)^{1-\mu}
$$

where $\mu$ is the elasticity of matching with respect to unemployment. In other words, while the literature often assumes match efficiency to be constant, here it is allowed to vary over time.

To estimate match efficiency fluctuations for the U.S. this paper uses a simple search and matching model. Because of its standard nature, the derivation of the model is left to the Appendix. ${ }^{4,5}$ The model boils down to two equations describing the evolution of unemployment and vacancies. The first equation is the law of motion for unemployment

$$
u_{t}=\left(1-m_{t-1}\left(v_{t-1} / u_{t-1}\right)^{1-\mu}\right) u_{t-1}+\rho_{x}\left(1-u_{t-1}\right) .
$$

where $\rho_{x}$ is the exogenous separation rate and the labor force has been normalized to 1 . Unemployment is thus the sum of newly separated workers and unemployed workers who did not find a job in the previous period. The second equation is a job creation condition equating the marginal costs of posting a vacancy with the marginal benefit of an extra worker

$$
\frac{\kappa}{m_{t}\left(v_{t} / u_{t}\right)^{-\mu}}=\beta\left(1-\rho_{x}\right)\left[\left(z_{t+1}-b\right)(1-\eta)-\eta \kappa v_{t+1} / u_{t+1}+\frac{\kappa}{m_{t+1}\left(v_{t+1} / u_{t+1}\right)^{-\mu}}\right],
$$

where $\kappa$ is the flow cost of posting vacancies, $\beta$ is the discount factor, $b$ is the value of non-work activities and $\eta$ is the worker bargaining power. The productivity and match efficiency shocks are assumed to follow AR(1) processes

$$
\begin{aligned}
\log \left(z_{t}\right) & =\left(1-\rho_{z}\right) \bar{z}+\rho_{z} \log \left(z_{t-1}\right)+\omega_{z, t}, \\
\log \left(m_{t}\right) & =\left(1-\rho_{m}\right) \bar{m}+\rho_{m} \log \left(m_{t-1}\right)+\omega_{m, t}
\end{aligned}
$$

\footnotetext{
${ }^{2}$ Modelling match efficiency as an unobserved component is related to Borowczyk-Martins et al. (2013) who point out that OLS-based estimates suffer from an endogeneity bias due to agents' unobserved behavior.

${ }^{3}$ Other papers have focused on how match efficiency shocks propagate. For example Fulanetto and Groshenny (2012) analyze a New Keynesian model and show that the propagation of match efficiency shocks depends on the form of hiring costs and on the presence of nominal rigidities.

${ }^{4}$ The Appendix is available online on the journal's website.

${ }^{5}$ The advantage of this approach is its direct link to the structural model in the second part of this paper. However, the Appendix shows that a very similar match efficiency estimate is obtained from a "model-free" estimation of only the matching function.
} 
where $\bar{z}, \bar{m}, \rho_{z}$ and $\rho_{m}$ are the respective unconditional means and autoregressive coefficients. The innovations are normally independently and identically distributed (iid) with zero means and standard deviations $\sigma_{z}$ and $\sigma_{m}$, respectively. Equations (2) to (5) form a state-space system, which I solve by linearization.

\subsection{Data}

Four time-series are used for the estimation: real GDP, two job finding rate measures and a measure of the job filling rate. ${ }^{6}$ While real GDP is informative about the aggregate productivity shock, the latter three help to identify the match efficiency shock. ${ }^{7}$ The first job finding rate measure is that proposed by Shimer (2005). Using the number of unemployed for less than 5 weeks $\left(u_{t}^{<5 W}\right)$ as a measure of newly separated workers he backs out the job finding rate from $(2)$ as $f_{t}=1-\left(u_{t}-u_{t+1}^{<5 W}\right) / u_{t}$. The second measure of the job finding rate is constructed from the longitudinally-matched individual-level data of the Current Population Survey (CPS). It gives the fraction of unemployed who subsequently report that they have found a job in the following month's survey. Finally, the vacancy yield taken from the Job Openings and Labor Turnover Survey (JOLTS) is used as a proxy for the job filling rate. It measures the flow of realized hires during a given month per reported job opening at the end of the previous month. ${ }^{8}$

While real GDP and Shimer's job finding rate are available from 1948Q1, the CPS-based measures starts in 1967Q3 and the vacancy yield is available from 2001Q1. For all time-series, the end of the sample is $2011 \mathrm{Q} 2 .{ }^{9}$ The use of two measures of the job finding probability has the advantage of estimating the model on a longer sample and at the same time accounting for some measurement issues in Shimer's job finding rate. ${ }^{10}$ Including a measure of the job filling probability helps to better pin down the match efficiency shock as the ratio of vacancies and unemployment enters inversely compared to the job finding rates. ${ }^{11}$

\subsection{Estimation}

Given that the estimation uses four observables, but the model is driven by only two structural shocks, measurement errors are added to the CPS-based job finding rate and the vacancy yield. These are assumed to have zero means, standard deviations $\sigma_{f}$ and $\sigma_{q}$, respectively, and to be uncorrelated with each other and with the structural shocks. The vacancy yield is assumed to be given by $\widetilde{q}_{t}=m_{t} u_{t}^{\mu_{u}} v_{t}^{\mu_{v}}$ where the assumption of constant returns to scale is relaxed as the vacancy yield is only a proxy for the true job filling probability.

The parameters of the shock processes and the matching elasticity are estimated while a standard calibration is used to obtain the other model parameters. In particular, the mean of aggregate productivity is normalized to $\bar{z}=1$, the discount factor is set to $\beta=0.99$ and the exogenous separation rate is fixed at $\rho_{x}=0.043$, the average quarterly value according to CPS data. Furthermore, the value of non-work activities $b$, the level of match efficiency $\gamma$ and the vacancy posting cost $\kappa$ are set such that the model matches the average job finding probability of 0.6 , based on CPS data, the quarterly job filling probability of $q=0.71$ following van Ours and Ridder (1992) and den Haan et al. (2000), and total costs of vacancies being $1 \%$ of output as in Andolfatto (1996). These targets imply a steady state unemployment rate of $6.7 \%$. Note that targeting the job filling probability $q$ implies a normalization. ${ }^{12}$ On the other hand the relative value of work and non-work activities is crucial for the dynamics of the model. The reason is that, for given values of $\beta, \rho_{x}, \mu, \eta$ and $m$, it determines the size of the surplus share accruing to the firm (and via the free entry condition also the per worker hiring costs). The closer the values of non-work and work activities, the stronger the responses of firm profits and therefore labor market tightness. ${ }^{13}$ Finally, there is little direct evidence on the value of the worker's bargaining power parameter. However, it is well understood that wage rigidity helps the model in matching the volatility of labor market variables. For this reason, the bargaining power is set such that the model matches the wage elasticity with respect to labor productivity of 0.64 as in Hagedorn and Manovskii (2011). All the other parameters $\left(\rho_{z}, \rho_{m}, \sigma_{z}, \sigma_{m}, \sigma_{f}, \sigma_{q}, \mu_{u}, \mu_{v}\right.$ and $\left.\mu\right)$ are estimated using maximum likelihood. ${ }^{14}$

\footnotetext{
${ }^{6}$ Within the model output is given by $y_{t}=z_{t}\left(1-u_{t}\right)$. All time-series are in quarterly frequencies and detrended with the HP filter with a smoothing coefficient of 1,600 .

${ }^{7}$ Using unemployment instead of GDP is problematic due to its high correlation with the job finding rate.

${ }^{8}$ The vacancy yield is not exactly the job filling rate due to time aggregation issues. Nevertheless, Davis et al. (2010) construct a measure of the job filling rate using the JOLTS vacancy yield data and conclude that "... the job-filling rate exhibits the same strong patterns as the vacancy yield" (p. 3).

${ }^{9}$ The different lengths of the time-series can be conveniently handled by the Kalman filter.

${ }^{10}$ Elsby et al. (2011) show that both measures move together very closely over the business cycle, but Shimer's job finding rate falls considerably more in the latest recession due to an increase of inflows with higher durations than five weeks.

${ }^{11}$ Estimating the model using data only on real GDP and Shimer's job finding rate delivers similar results and is discussed in more detail in the online Appendix. However, match efficiency is somewhat more volatile which is consistent with the point made by Elsby et al. (2011).

${ }^{12}$ Reducing this target by one half will double the number of vacancies (and labor market tightness), halve the vacancy posting costs and reduce match efficiency by a factor of $2^{1-\mu}$ without affecting the dynamics of the model.

${ }^{13}$ The calibration procedure adopted here implies that larger values of non-work activities are associated with smaller hiring costs.

${ }^{14}$ Further details on the state-space specification and the estimation are in the online Appendix.
} 


\section{Estimation results}

All the model parameters are summarized in Table (1). The matching elasticity is estimated to be 0.567 which is within the bounds of estimates reported in the survey of Petrongolo and Pissarides (2001). As explained above, the two parameters crucial for the dynamics of the model are the value of non-work activities and workers' bargaining power. The value of non-work activities of 0.935 is at the higher end of the values found in the literature, very close to that used in Hagedorn and Manovskii (2011) and Monacelli et al. (2010). The value of workers' bargaining power of 0.255 is in between a symmetric bargaining setup and values found in Hagedorn and Manovskii (2011).

Figure (1) plots the match efficiency shock together with the NBER recessions showing its pro-cyclical nature. The correlations with the cyclical component of the unemployment rate and real GDP are -0.81 and 0.55 , respectively. This means that recessions are times when unemployed workers find it harder to get jobs not only because there are less vacancies and more unemployed competing for them, but also because the efficiency of matching declines. ${ }^{15}$

While match efficiency dropped substantially during the latest recession, other recessions were characterized by declines of similar magnitudes. In this sense the most recent downturn was not an exception. The 1991 and 2001 recessions were, however, slightly atypical with match efficiency experiencing its troughs a few periods after the end of the recession.

To gauge how important match efficiency is for labor market developments Figure (2) shows a counter-factual unemployment rate which is constructed under the assumption that match efficiency is held constant at its unconditional mean. ${ }^{16}$ On average, match efficiency drops in recessions increase the unemployment rate by 0.58 percentage points. During the three downturns with the largest unemployment increases (1973, 1982 and 2008) match efficiency accounted for 0.91 percentage points, or $23 \%$ of the observed unemployment increases. ${ }^{17}$

\section{Match efficiency as an endogenous variable}

The previous section documented that in recessions falling match efficiency exacerbates unemployment increases and that this effect can be substantial. However, the variation in match efficiency over time was assumed to be exogenous to the model, resulting from realizations of a shock. This section presents a model in which match efficiency fluctuates endogenously resulting from agents' optimizing behavior. The model is shown to account for $1 / 2$ of the variation in match efficiency estimated in the previous section.

In particular, the proposed model rests on firing costs and endogenous separations in which the job finding rate depends not only on vacancies and unemployment but also on firms' hiring standards, or the "rejection rate" of new hires. Importantly, hiring standards move endogenously with the cycle in a counter-cyclical manner, consistent with the data. For empirical evidence on counter-cyclical hiring standards in the U.S. see e.g. Bewley (1999) and Devereux (2002). Similar results are found for Western Germany by Pollmann-Schult (2005) and Buttner et al. (2009) and for the Netherlands by Teulings and Koopmanschap (1989) and van Ours and Ridder (1995). Quintini (2011) presents related evidence on counter-cyclical over-qualification in a sample of 13 European countries.

\subsection{Structural model explaining match efficiency fluctuations}

This subsection describes a standard search and matching model with endogenous separations in the spirit of Mortensen and Pissarides (1994), augmented with firing costs. There is a representative household consisting of a continuum of risk neutral workers of unit mass who can be either employed or unemployed. Every period each worker draws a productivity level $p_{i, t}$ from a constant distribution $F$ which is the same for both the employed and the unemployed. For tractability, the productivity draws are assumed to be independently and identically distributed. ${ }^{18}$ Members of the household pool their incomes from employment and non-employment activities and the household maximizes lifetime utility

$$
E_{0} \sum_{t=0}^{\infty} \beta^{t} c_{t}
$$

subject to the budget constraint

$$
c_{t}=y_{t}+b u_{t}
$$

where $\beta$ is the discount factor, $c_{t}$ is aggregate consumption, $y_{t}$ is aggregate production, $b u_{t}$ is non-employment income and where the costs of posting vacancies are assumed to be paid to the household.

\footnotetext{
${ }^{15}$ Figure (1) shows a sharp increase in match efficiency at the end of the sample. However, the strength of this reversal should be taken with care due to the use of HP-filtered data, which is known to suffer from endpoint problems.

${ }^{16}$ The steady state relationship $u_{t}=s_{t} /\left(s_{t}+f_{t}\right)$, where $s_{t}$ is the separation rate, is known to track the actual unemployment rate very well. Using this relationship, the counterfactual unemployment rate is constructed by replacing the actual job finding probability with one in which match efficiency is fixed at its mean, $f_{t}^{*}=\bar{m}\left(v_{t} / u_{t}\right)^{1-\mu}$.

${ }^{17}$ During the last recession match efficiency accounted for 1.3 percentage points of the unemployment rate increase.

${ }^{18}$ With iid individual productivity shocks it does not matter for the mechanics of the model whether the shock is worker or job specific. The interpretation of why match efficiency fluctuates would, however, be different. If shocks were job-specific, match efficiency would vary due to a pro-cyclical fraction of jobs that are productive enough to operate.
} 


\subsubsection{Employment relationships}

Employment relationships consist of a worker-firm pair. Production is given by $z_{t} p_{i, t}$, where $z_{t}$ is aggregate productivity. Employment relationships can be terminated for exogenous reasons and this happens at rate $\rho_{x}$. After observing aggregate and idiosyncratic productivity, but before production, the worker-firm pair decides whether or not to endogenously separate. In the event of separation, there is no production and the worker joins the unemployment pool. When an existing employment relationship endogenously terminates, a firing cost $\phi$ must be paid by the firm. The firing cost is not a transfer to the worker (severance payment), but rather the administrative and legal costs related to separation. New employment relationships can also be rejected (separated) prior to production, in which case no firing cost needs to be paid.

Let $S_{t}^{j}\left(p_{i, t}\right)$ be the joint surplus of the employment relationship with worker-specific productivity $p_{i, t}$, and $j=N, E$ indicating a new and an existing employment relationship, respectively. The worker and firm negotiate over the division of this surplus according to Nash bargaining with $\eta$ being the bargaining weight of the worker. The employment relationship continues as long as $S_{t}^{j}\left(p_{i, t}\right)>0$. Define threshold values for worker-specific productivity, $\widetilde{p}_{t}^{N}\left(\widetilde{p}_{t}^{E}\right)$, such that new (existing) relationships decide to separate if $p_{i, t} \leq \widetilde{p}_{t}^{N}\left(p_{i, t} \leq \widetilde{p}_{t}^{E}\right)$.

Associated with the cutoff values are the endogenous separation, $F\left(\widetilde{p}_{t}^{E}\right)$, and rejection rates, $F\left(\widetilde{p}_{t}^{N}\right)$, respectively. The total separation rate and rejection rate (firms' hiring standards) are then defined as

$$
\begin{aligned}
& s_{t}=\rho_{x}+\left(1-\rho_{x}\right) F\left(\widetilde{p}_{t}^{E}\right), \\
& r_{t}=\rho_{x}+\left(1-\rho_{x}\right) F\left(\widetilde{p}_{t}^{N}\right) .
\end{aligned}
$$

The joint surplus, $S_{t}^{j}\left(p_{i, t}\right)$, is defined as the payoffs of the worker and firm obtained in the relationship, $W_{t}^{j}\left(p_{i, t}\right)+$ $J_{t}^{j}\left(p_{i, t}\right)$, net of the sum of their outside options. Let $U_{t}$ be the worker outside option. Firms take into account firing costs giving rise to outside options $V_{t}$ and $V_{t}-\phi$ for new and existing employment relationships, respectively. The value of being in the unemployment pool for a worker is defined as

$$
U_{t}=b+E_{t} \beta\left(\begin{array}{cc}
\left(1-\rho_{x}\right) \bar{m} \theta_{t}^{1-\mu} \int_{\widetilde{p}_{t+1}^{N}}^{\infty}\left(W_{t+1}^{N}\left(p_{t+1}\right)-U_{t+1}\right) d F\left(p_{t+1}\right) \\
+U_{t+1}
\end{array}\right),
$$

where $b$ is the value of home production, $\theta=v_{t} / u_{t}$ is the ratio of vacancies and unemployment, and $\bar{m} \theta_{t}^{1-\mu}$ gives the probability with which an unemployed worker is matched with a vacancy, where $\bar{m}$ is a scaling constant and $\mu$ is the elasticity of matching with respect to unemployment. The value for a firm of having an unfilled vacancy is given by

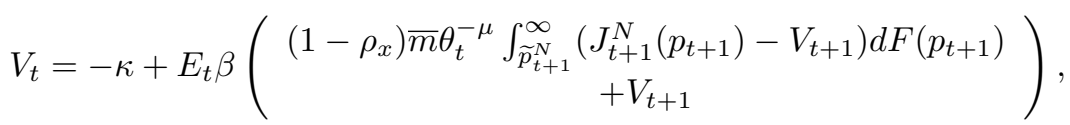

where $\kappa$ is the flow cost of having an open vacancy and $\bar{m} \theta_{t}^{-\mu}$ is the probability a firm with an open vacancy is matched with an unemployed worker.

The value of being in an employment relationship for a worker is given by

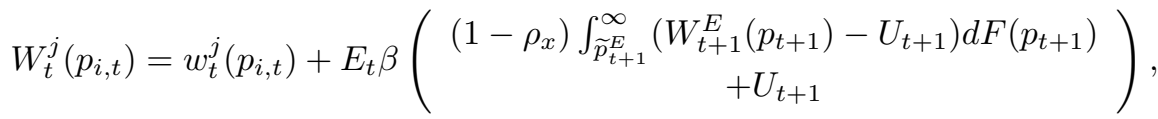

where $w_{t}^{j}\left(p_{i, t}\right)$ is the wage rate. Finally, the value of an employment relationship for the firm is

$$
J_{t}^{j}\left(p_{i, t}\right)=z_{t} p_{i, t}-w_{t}^{j}\left(p_{i, t}\right)+E_{t} \beta\left(\begin{array}{c}
\left(1-\rho_{x}\right) \int_{\widetilde{p}_{t}^{E}}^{\infty}\left(J_{t+1}^{E}\left(p_{t+1}\right)-V_{t+1}\right) d F\left(p_{t+1}\right) \\
-F\left(\widetilde{p}_{t+1}^{E}\right) \phi+V_{t+1}
\end{array}\right) .
$$

\subsubsection{Vacancy posting, wages and output}

Under the assumption of free entry the value of having an open vacancy is driven down to zero and one can then express the vacancy posting condition as

$$
\kappa=E_{t} \beta\left(1-\rho_{x}\right) \bar{m} \theta_{t}^{-\mu} \int_{\widetilde{p}_{t+1}^{N}}^{\infty} J_{t+1}^{N}\left(p_{t+1}\right) d F\left(p_{t+1}\right) .
$$

Wages are set according to Nash bargaining giving rise to a familiar wage structure for workers in new and existing employment relationships, respectively ${ }^{19}$

$$
w_{t}^{N}\left(p_{i, t}\right)=\eta\left(z_{t} p_{i, t}-\beta\left(1-\rho_{x}\right) \phi+\kappa \theta_{t}\right)+(1-\eta) b,
$$

\footnotetext{
${ }^{19}$ The details of the derivation of wages are left to the online Appendix.
} 


$$
w_{t}^{E}\left(p_{i, t}\right)=\eta\left(z_{t} p_{i, t}+\left(1-\beta\left(1-\rho_{x}\right)\right) \phi+\kappa \theta_{t}\right)+(1-\eta) b .
$$

Finally, aggregate output is defined as

$$
y_{t}=z_{t} n_{t}\left(\omega_{t} H\left(\widetilde{p}_{t}^{N}\right)+\left(1-\omega_{t}\right) H\left(\widetilde{p}_{t}^{E}\right)\right)
$$

where $\omega_{t}=\frac{\bar{m} \theta_{t-1}^{1-\mu} u_{t-1}\left(1-r_{t}\right)}{1-u_{t}}$ is the fraction of new employment relationships in the total and $H(x)=E_{t}[p \mid p \geq x]=$ $\int_{x}^{\infty} p \frac{d F(p)}{1-F(x)}$ is the average productivity of workers with an idiosyncratic draw above $x$.

\subsubsection{Match efficiency and unemployment}

Matching occurs at the end of each period with matched workers being available for production in the next period. The number of matches in period $t$, and thus new employment relationships in period $t+1$, is given by

$$
M_{t}=\bar{m} u_{t}^{\mu} v_{t}^{1-\mu}
$$

Notice, however, that the number of unemployed workers that end up in productive employment relationships in the next period depends on firms' hiring standards, $r_{t}$, as new workers can still be rejected. Hence, the probability that an unemployed worker finds a job and that a firm fills an open vacancy are given by

$$
\begin{gathered}
f_{t}=\frac{M_{t}\left(1-r_{t+1}\right)}{u_{t}}=\bar{m} \theta_{t}^{1-\mu}\left(1-r_{t+1}\right), \\
q_{t}=\frac{M_{t}\left(1-r_{t+1}\right)}{v_{t}}=\bar{m} \theta_{t}^{-\mu}\left(1-r_{t+1}\right) .
\end{gathered}
$$

Therefore, the model counterpart of measured match efficiency from Section 3 is given by

$$
m_{t}=\bar{m}\left(1-r_{t+1}\right) \text {. }
$$

Finally, unemployment evolves according to

$$
u_{t}=\left(1-\bar{m} \theta_{t-1}^{1-\mu}\left(1-r_{t}\right)\right) u_{t-1}+s_{t}\left(1-u_{t-1}\right),
$$

where unemployment this period is a combination of newly separated workers and last period's unemployed who either were not matched with a vacancy, or who were matched but did not meet firms' hiring standards.

\section{Hiring-standards-driven match efficiency fluctuations}

This section first calibrates the model described in the previous paragraphs. Second, based on this calibration the model dynamics are analyzed with a particular focus on how well the model is able to capture fluctuations in match efficiency estimated in Section 3. Finally, this section ends with a discussion of the main mechanism driving match efficiency fluctuations.

\subsection{Calibration}

The calibration procedure is identical to that in Section 2. In addition, however, the current model contains three new parameters pertaining to the worker-specific productivity distribution and firing costs. The worker-specific productivity shocks are assumed to be distributed iid according to a log-normal distribution, $\log (p) \sim N\left(\mu_{F}, \sigma_{F}^{2}\right)$. $\mu_{F}$ is such that average worker productivity is normalized to 1 and $\sigma_{F}$ is set to match the volatility of the separation rate relative to $(\log )$ output volatility of 0.21 , consistent with CPS data.

Finally, in order to calibrate the firing cost parameter, evidence from Bentotila and Bertola (1990) is combined with the Employment Protection Legislation (EPL) index published by the OECD. The EPL is a weighted average of indicators capturing protection of regular workers against individual dismissals, requirements for collective dismissals and regulation of temporary employment. Bentotila and Bertola (1990) provide estimates of firing costs as a fraction of annual wages for France, Germany, Italy and the UK in the period between 1975 and 1986. Assuming that the EPL is proportional to the estimates provided by Bentotila and Bertola and that the UK institutional environment is closest to that of the U.S., the implied firing costs are equal to $17.9 \%$ of quarterly wages. Therefore, firing costs are set to $\phi=0.179 \bar{w}^{E}$, where $\bar{w}^{E}$ is the steady state wage for workers in existing employment relationships. ${ }^{20}$ All the model parameters are summarized in Table (2).

\footnotetext{
${ }^{20}$ Bentotila and Bertola (1990) estimate that firing costs in the UK constitute $25 \%$ of the annual wage between 1975 and 1986 . The regular employment contract EPL in 1985 is 0.95 for the U.K. and 0.17 for the U.S. implying that firing costs in the U.S. were equal to $4.47 \%$ of annual wages. The EPL for the U.S. was 0.17 throughout the period between 1985 and 2008 (the last available year).
} 


\subsection{Model-based match efficiency}

Figure (3) displays impulse response functions to a negative one-standard deviation aggregate productivity shock. At the onset of a recession, and as in a simple search and matching model, unemployment increases and vacancies drop (top row). However, at the same time firms are willing to hold on to and hire only relatively more productive workers, i.e. firms' hiring standards rise, which is reflected in an increase of the separation and rejection rates (middle row). The increase in the rejection rate can be equivalently characterized as a decrease in model-based match efficiency which reinforces the drop in the job finding probability, i.e. more than what is predicted by the decline in labor market tightness alone (bottom row).

Table (3) compares second moments of labor market variables from the simulated model to their empirical counterparts in the U.S. economy. ${ }^{21}$ The model is able to explain $46 \%$ of the observed match efficiency volatility found in Section 3. The model also replicates the pro-cyclicality of model-based match efficiency with a correlation coefficient of 0.83 and -0.77 with output and unemployment, respectively. ${ }^{22}$

Finally, model-based match efficiency is compared to that found in the data. To this end, I use data for real GDP to back out the implied aggregate productivity shock by inverting the model's policy function. The implied shock series is then used to simulate the model. Figure (4) shows that model-based match efficiency tracks the estimated one quite well (correlation coefficient of 0.41). However, the model explains relatively less of the observed match efficiency movements after 1985. Specifically, the model fails to capture the declines in match efficiency that lasted into the early recovery phases during the 1991 and 2001 recessions. These downturns were characterized by jobless recoveries and therefore using real GDP to recover match efficiency will not deliver substantial declines in this period. This indicates that especially in the last two recessions match efficiency was driven also by other forces than just changing firms' hiring standards. Nevertheless, also in this later period, the model can explain $25 \%$ of the empirical match efficiency fluctuations.

\subsection{Discussion of main model mechanism}

This section further discusses the modelling choices directly related to firms' hiring standards and their interpretation. The next paragraphs also explain the propagation mechanism in more detail and provide some evidence about the plausibility of its magnitude.

In the model, match efficiency fluctuates because the rejection rate endogenously changes over the business cycle. The interpretation provided in the paper is that workers are heterogeneous in their productivity and the rejection rate reflects hiring standards of homogeneous firms. In reality, however, firms (jobs) also differ in their skill requirements. The simplifying assumption of homogeneous firms is made for tractability, but a more detailed treatment as in e.g. Gautier (2002) is unlikely to change the main working of the model.

In this model, the counter-cyclicality of firms' hiring standards leads to an increase in average worker productivity in recessions. However, empirical evidence suggests that average match quality (typically measured by job duration) declines in downturns (see e.g. Bowlus, 1995). ${ }^{23}$ These observations are not in contradiction as being able to hire workers with higher skills for a given job in recessions does not necessarily imply a better match. Indeed, empirical evidence suggests that overqualified workers are more likely to quit their job (Quintini, 2011).

The model's ability to quantitatively explain match efficiency fluctuations rests on the magnitude of rejection rate fluctuations. The calibration of the worker productivity distribution puts discipline on this magnitude by targeting the (observed) volatility of the separation rate. However, rejection rate fluctuations are magnified, because firing costs push the relevant threshold of worker-productivity into an area of the distribution with higher mass. An upward sloping density around the thresholds is not unreasonable given that they lie in the lower tail of the distribution. This effectively means that the unemployment pool is populated by a larger mass of marginal workers, compared to the employment pool. ${ }^{24}$ Finally, Devereux (2002) shows that a 1 percentage point increase in the unemployment rate is related to a $0.8 \%(0.6 \%)$ rise in the proportion of college graduates (workers with at least a high school diploma) among new hires. Given that their respective fractions among new hires are $21 \%$ ( $86 \%$ ) and that the college/high school (high school/8th grade) wage premium is about $50 \%$ (30\%) according to Golding and Katz (2007), this translates into a $0.20 \%$ increase in average productivity of new workers. In the model, an increase in the unemployment rate by 1 percentage point is associated with a $0.25 \%$ increase in average productivity of new hires. This suggests that the strength of the proposed mechanism is not implausible.

\footnotetext{
${ }^{21}$ The model economy is simulated 1,000 times. Each time 1,254 quarters are simulated and the first 1,000 are dropped to obtain 254 observations as in the empirical part. The reported statistics are averages over the 1,000 simulations.

${ }^{22}$ The model replicates second moments of other labor market variables relatively well.

${ }^{23}$ Note, however, that there is also evidence that when focusing on only new hires of previously unemployed workers match quality does not seem to fall during recessions, see e.g. del Río (2011).

${ }^{24}$ To illustrate this point consider for instance the group of workers with less than a high school education, workers from racial and minority groups and young workers. Elsby et al. (2011) document that these groups of workers have higher separation rates, implying that they are composed of a relatively larger fraction of marginal workers. While these groups account for $8.4,10.8$ and $14.3 \%$ of employment, respectively, they are relatively more represented in the unemployment pool accounting for $13.5,21.1$ and $32.8 \%$, respectively.
} 


\section{Conclusion}

Modeling flows from unemployment to employment as a function of unemployment and vacancies alone implies that a given number of searching workers and employers always leads to the same number of hires. This is unlikely to hold in reality, pointing to other sources of variation, here defined as match efficiency. Using a simple search and matching model with an aggregate productivity and match efficiency shock as exogenous driving forces, this paper estimates match efficiency to be pro-cyclical and responsible for $1 / 4$ of unemployment increases during the most severe recessions.

However, match efficiency may be an outcome of agents' optimizing behavior rather than an exogenous shock to the matching technology. In particular, this paper shows that a model with firing costs and endogenous separations can generate pro-cyclical movements in match efficiency and explain about $1 / 2$ of its volatility as found in the data. The reason is that in a recession firms increase their hiring standards, which leads to a fall in the fraction of acceptable employment relationships that can be formed with unemployed workers. When one considers a matching function with labor market tightness as its only input, changes in firms' hiring standards will be represented as movements in measured match efficiency.

Other channels brought up in the literature, such as cyclical geographical mobility of workers, the skill composition of the unemployment pool or the search intensity on both sides of the labor market, may also cause match efficiency to fluctuate. These seem to be more prominent in the period after 1985 when firms' hiring standards explain relatively less of the match efficiency movements measured in the data.

\section{References}

Andolfatto, D., 1996. Business cyles and labor market search. American Economic Review 86, $112-132$.

Barlevy, G., 2011. Evaluating the role of labor market mistmatch in rising unemployment. Economic Perspectives, Federal Reserve Bank of Chicago.

Barnichon, R., 2010. Building a composite Help-Wanted index. Economics Letters 109, 175-178.

Barnichon, R., Figura, A., 2013. Labor market heterogeneities and the aggregate matching function. Mimeo.

Bentotila, S., Bertola, G., 1990. Firing costs and labour demand: How bad is eurosclerosis? The Review of Economic Studies 57, 381-402.

Bewley, T., 1999. Why Wages Don't Fall During a Recession. Harvard University Press.

Borowczyk-Martins, D., Jolivet, G., Postel-Vinay, F., 2013. Accounting for endogenous search behavior in matching function estimation. Review of Economic Dynamics 16, 440-451.

Bowlus, A.J., 1995. Matching workers and jobs: Cyclical fluctuations in match quality. Journal of Labor Economics 13 , 335-350.

Buttner, T., Jacobebbinghaus, P., Ludsteck, J., 2009. Occupational upgrading and the business cycle in West Germany. IAB Discussion Paper no. 2009-34.

Davis, S., Faberman, J., Haltiwanger, J., 2010. The establishment-level behavior of vacancies and hiring. NBER Working Paper no. 16265.

Devereux, P.J., 2002. Occupational upgrading and the business cycle. Labour 16, 423-452.

Dickens, W.T., 2011. A new method for estimating time variation in the NAIRU. Mimeo.

Elsby, M.W.L., Hobijn, B., Sahin, A., Valletta, R.G., 2011. The labor market in the Great Recession: an update. Federal Reserve Bank of San Francisco, Working Paper 2011-29.

Fulanetto, F., Groshenny, N., 2012. Matching efficiency and business cycle fluctuations. Norges Bank Working Paper.

Gautier, P., 2002. Unemployment and search externalities in a model with heterogeneous jobs and workers. Economica 69, 21-40.

den Haan, W.J., Ramey, G., Watson, J., 2000. Job destruction and propagation of shocks. American Economic Review $90,482-498$.

Hagedorn, M., Manovskii, I., 2011. Productivity and the labor market: Co-movement over the business cycle. International Economic Review 52, 603-619.

Herz, B., van Rens, T., 2011. Structural unemployment. Barcelona GSE Working Paper no. 568.

Kuang, K., Valletta, R., 2010. Extended unemployment and UI benefits. Federal Reserve Bank of San Francisco, Economic Letter $2010-12$

Lubik, T.A., 2011. The shifting and twisting beveridge curve: An aggregate perspective. Mimeo.

Monacelli, T., Perotti, R., Trigari, A., 2010. Unemployment fiscal multipliers. Journal of Monetary Economics 57, $531-553$.

Mortensen, D., Pissarides, C., 1994. Job creation and job destruction in the theory of unemployment. Review of Economic Studies 61, $397-415$.

van Ours, J., Ridder, G., 1992. Vacancies and the recruitment of new employees. Journal of Labor Economics 10, $138-155$.

van Ours, J., Ridder, G., 1995. Job matching and job competition: Are lower educated workers at the back of job queues? European Economic Review 39, 1717-1731.

Petrongolo, B., Pissarides, C.A., 2001. Looking into the black box: A survey of the matching function. Journal of Economic Literature 39, 390-431.

Pollmann-Schult, M., 2005. Crowding out of unskilled workers in the business cycle: Evidence from West Germany. European Sociological Review 21, 467-480.

Quintini, G., 2011. Right for the job: Over-qualified or under-skilled? OECD Employment Outlook , $191-233$.

del Río, J.M., 2011. Job duration over the business cycle. Federal Reserve Bank of Kansas City, mimeo.

Sahin, A., Song, J., Topa, G., Violante, G.L., 2011. Measuring mismatch in the U.S. labor market. Federal Reserve Bank of New York.

Shimer, R., 2005. The cyclical behavior of equilibrium unemployment and vacancies. American Economic Review 95, $25-49$.

Sterk, V., 2010. Home equity, mobility and macroeconomic fluctuations. Mimeo, University of Amsterdam.

Teulings, C., Koopmanschap, M., 1989. An econometric model of crowding out of lower educational levels. European Economic Review $33,1653-1664$.

Veracierto, M., 2011. Worker flows and matching efficiency. Economic Perspectives, Federal Reserve Bank of Chicago. 


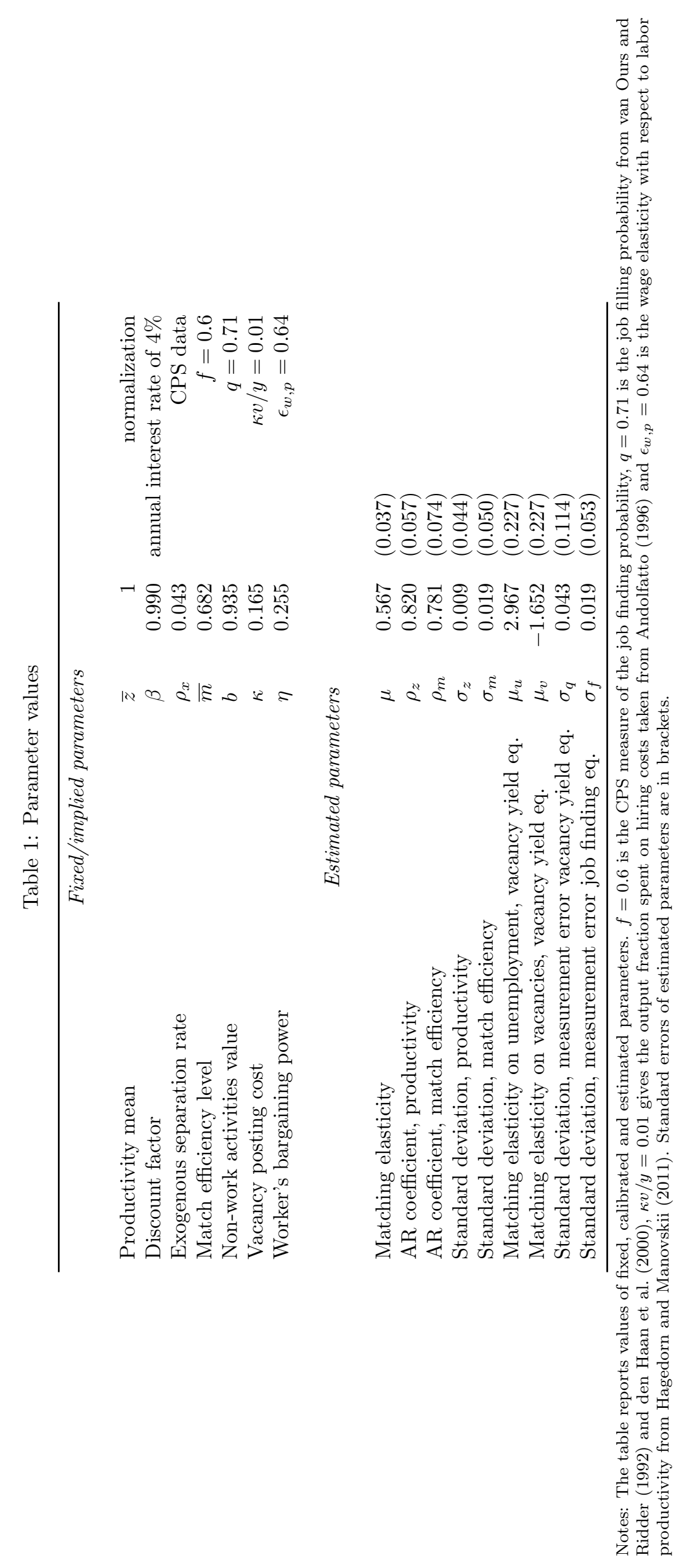




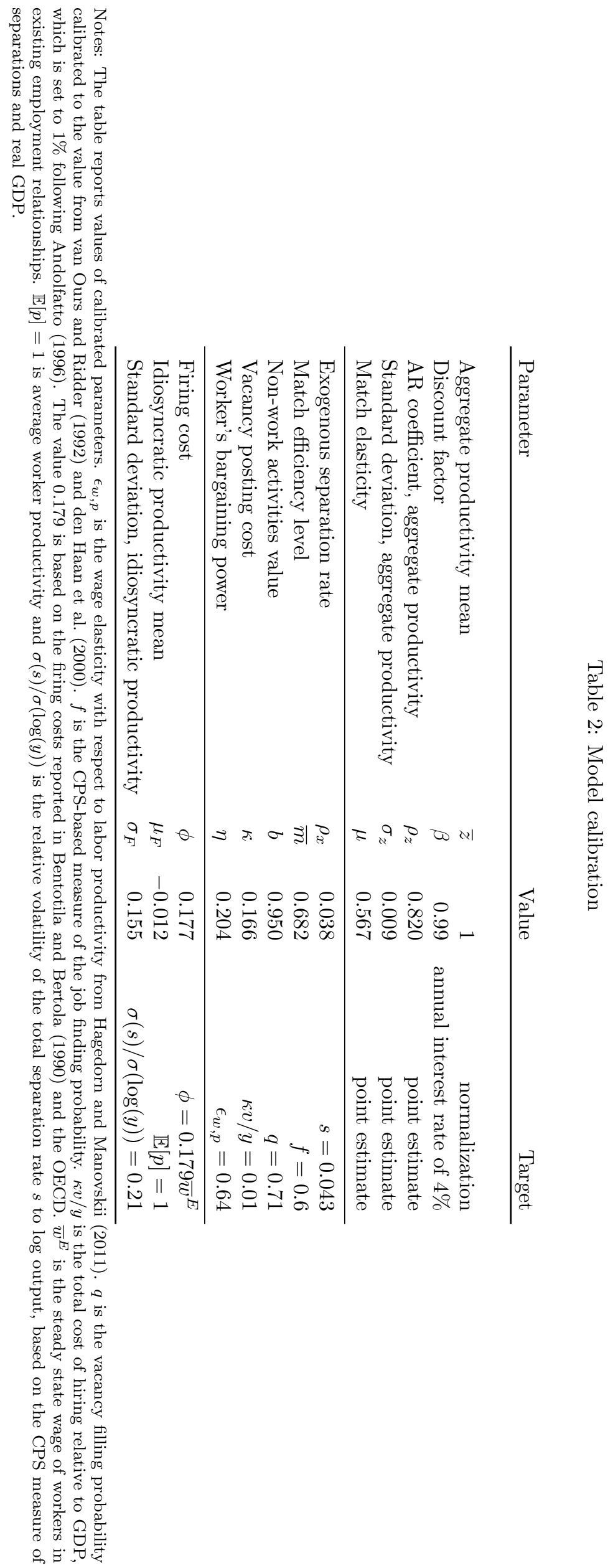


Table 3: Relative standard deviations

\begin{tabular}{lrrrrr} 
& $\mathrm{m}$ & $\mathrm{s}$ & $\mathrm{f}$ & $\mathrm{u}$ & $\mathrm{v}$ \\
\hline data & 1.62 & 0.21 & 1.97 & 0.49 & 0.26 \\
model & 0.75 & 0.21 & 1.95 & 0.47 & 0.24 \\
& $(0.14)$ & $(0.01)$ & $(0.06)$ & $(0.02)$ & $(0.02)$
\end{tabular}

Notes: The table reports standard deviations relative to output (real GDP) volatility, where $m$ is (the log of) match efficiency, $s$ is the separation rate, $f$ is the job finding probability, $u$ is the unemployment rate and $v$ is the vacancy rate. The data are seasonally adjusted and detrended with an HP filter with smoothing coefficient 1,600 for the common sample period of $1967 \mathrm{Q} 3$ to $2011 \mathrm{Q} 2$. The unemployment rate is taken from the BLS, the vacancy rate is defined as $v /(v+e)$, where $v$ is the level of vacancies based on the composite help wanted index proposed by Barnichon (2010) and $e$ is total employment published by the BLS. The job finding and separation rates are the CPS-based measures and measured match efficiency is taken from Section 3. The model is simulated 1 , 000 times, each with 1, 254 periods and the first 1,000 periods discarded. The model-based variables are treated in the same way as the data. The reported statistics are averages over the 1,000 simulations with standard deviations across simulations in brackets.

Figure 1: Match efficiency

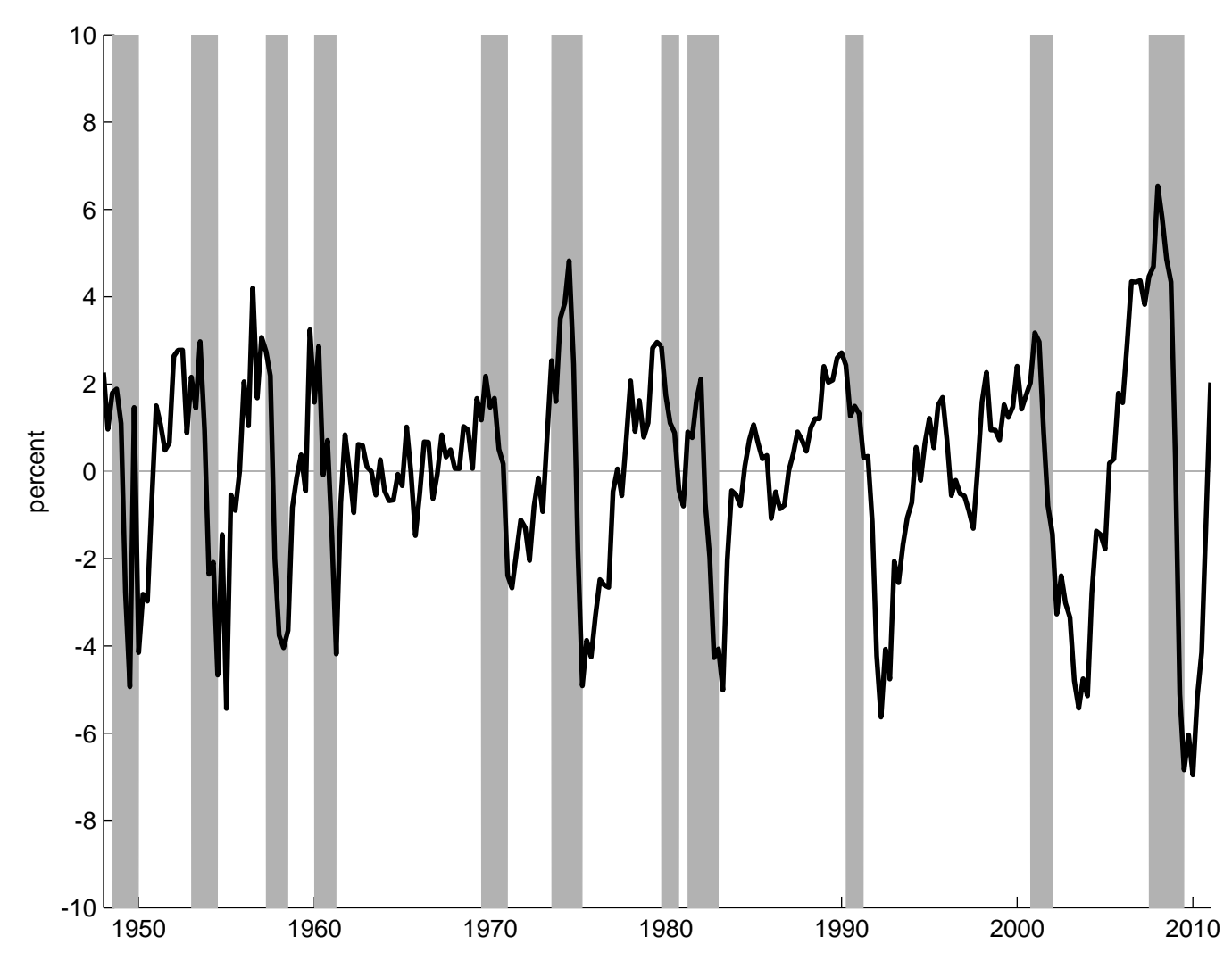

Notes: Estimated match efficiency expressed as percent deviations from mean together with NBER recessions (shaded areas). 
Figure 2: Actual and counterfactual unemployment rates

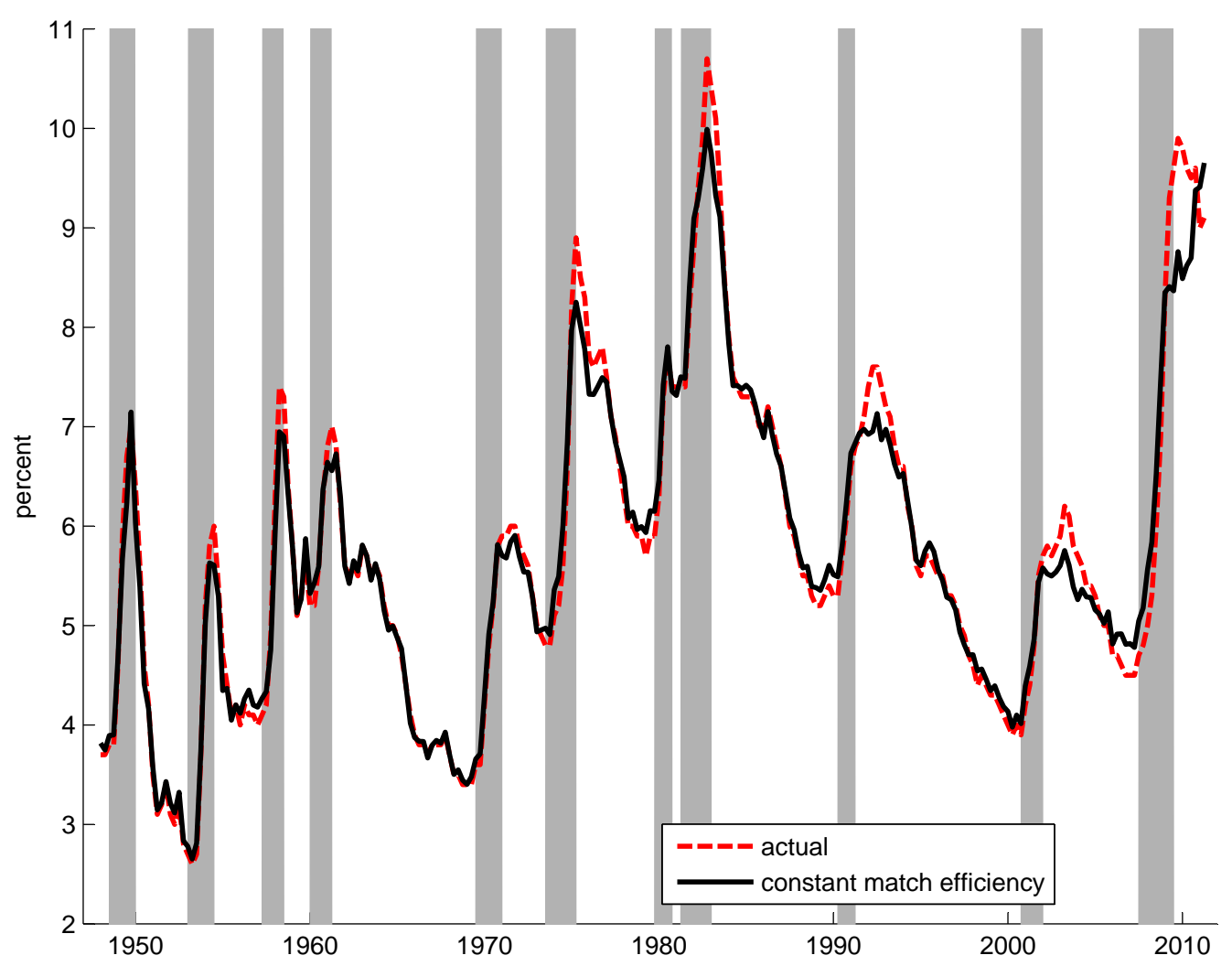

Notes: Actual unemployment rate together with its counterfactual constructed by fixing match efficiency at its unconditional mean. Shaded areas are NBER recessions. 
Figure 3: Impulse response functions
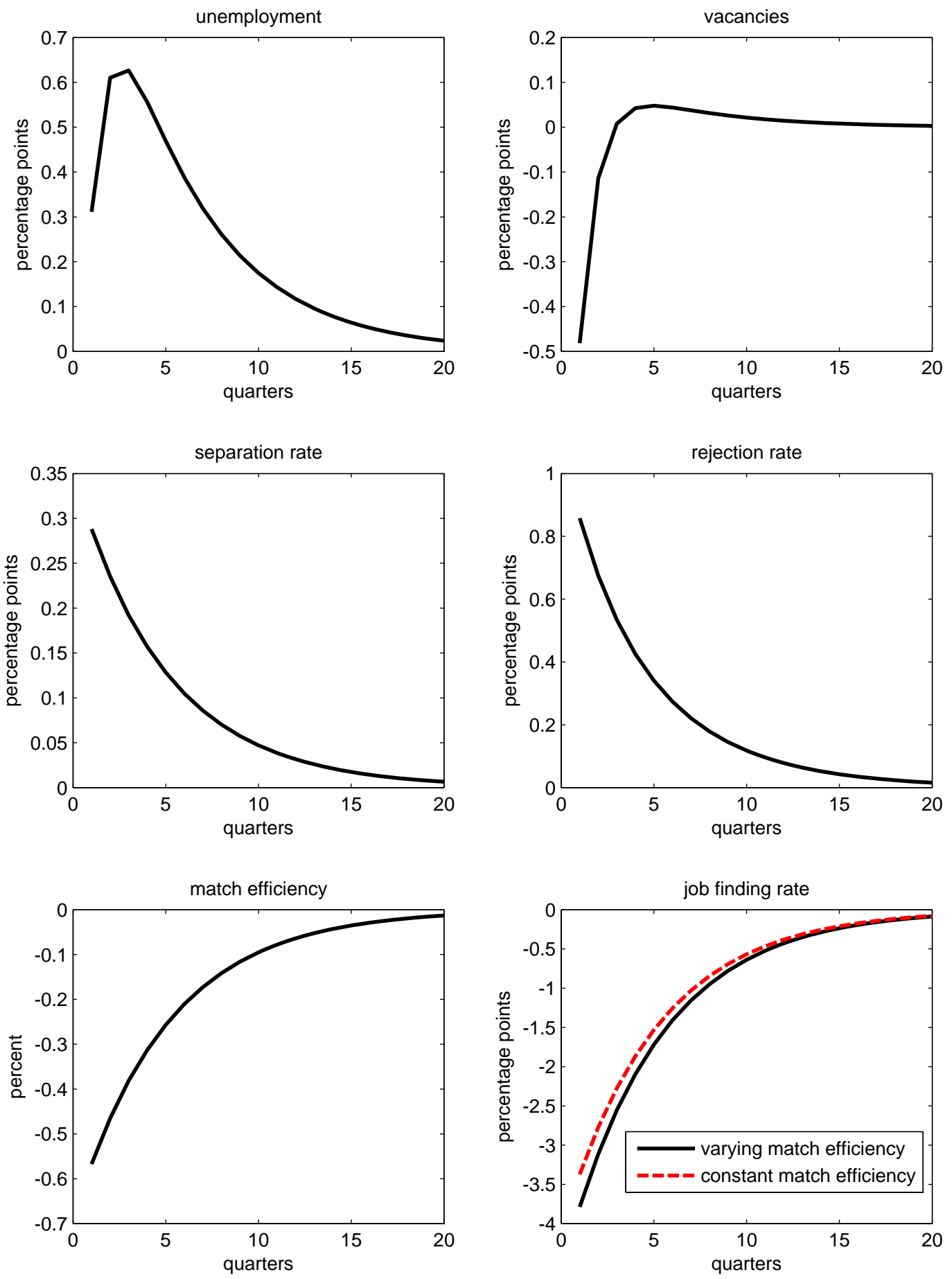

Notes: Impulse response functions to a negative one-standard deviation shock to aggregate productivity. 
Figure 4: Actual and model-based match efficiency

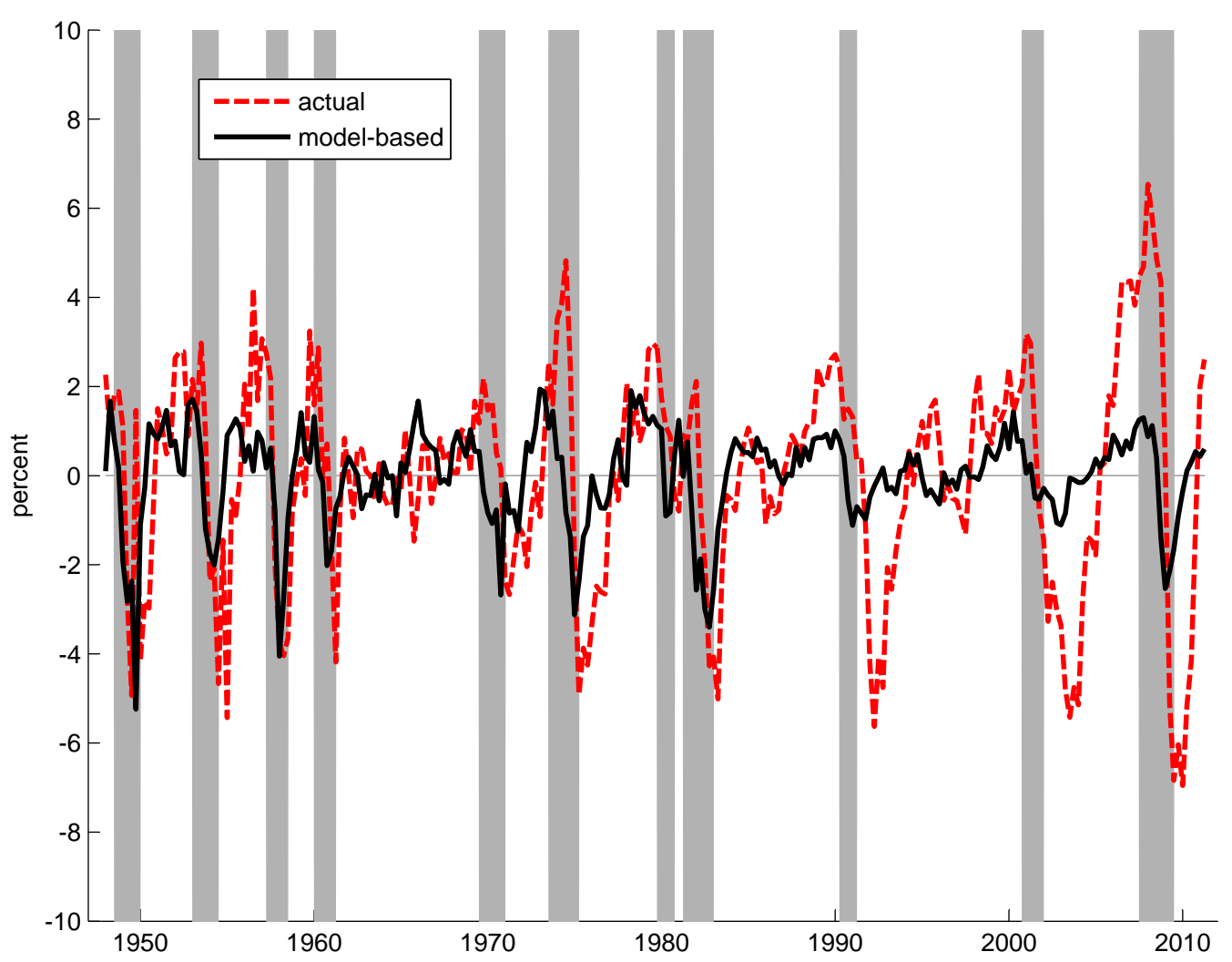

Notes: "Actual" stands for match efficiency from Section 3. Using HP-filtered data on log real GDP and inverted policy rules of the model one can back out the implied shock series that generates the observed output movements. These shocks are then fed through the model which gives the "model-based" match efficiency. 